RU Междометия как релевантный элемент эмотивной лексики адыгских языков

\author{
Афаунова А. А.
}

\begin{abstract}
Аннотация. Цель исследования заключается в выявлении многообразия функциональных и семантических особенностей междометных слов адыгских языков. Научная новизна статьи определяется тем, что впервые в кабардино-черкесской лингвистике анализируются релевантные функции междометий и вопрос образования фразеологических единиц с их участием. Использование подобных фразеологизмов является типичным для структуры исследуемых языков. Полученные результаты показали, что междометия выступают ярким и уникальным представителем эмоциональной сферы речевой деятельности человека. Междометия наряду с основным своим предназначением - передавать эмоции и чувства - являются значимой аффективной составляющей лингвокультуры адыгских языков.
\end{abstract}

\title{
EN Interjections as Relevant Component of Emotive Vocabulary of the Adyghe Languages
}

\section{Afaunova A. A.}

\begin{abstract}
The paper aims to reveal functional and semantic peculiarities of the Adyghe interjections. Scientific originality of the study is conditioned by the fact that for the first time in the Kabardino-Circassian linguistics, the author analyses pragmatic functions of interjections. Special attention is paid to studying formation of emotive phraseological units containing interjections. The findings indicate that interjections most clearly and vividly objectify human emotions. Along with their basic function - to transfer emotions and feelings - interjections perform an important language and cultural function.
\end{abstract}

\section{Введение}

Междометия присутствуют практически во всех языках и в зависимости от структуры речи и характера высказывания занимают в них различное положение. Интерес к междометиям начал проявляться в ходе анализа происхождения языка, где в последующем выделили несколько предположений, среди которых была и междометная гипотеза. Главное в ней было то, что эмоциональные выкрики дали толчок к созданию языка. По мнению представителей данной гипотезы, первобытный человек прошел тот же процесс формирования речи, что и ребенок, который учится разговаривать.

В рамках адыгских языков междометия, так же как и в других языках, занимают неоднозначную позицию. Некоторые лингвисты указывают на их несостоятельность в грамматике и на нецелесообразность их исследования, другие выделяют их отличительные и уникальные черты и функции.

Актуальность предлагаемого исследования определяется непрерывным развитием адыгских языков, что приводит к появлению новых лексических единиц, которые, несомненно, влияют как на расширение словарного состава, так и на изменение всей лексикологии. В современной лингвистике приоритетным становится изучение языковых процессов и явлений не только с позиции чисто грамматических особенностей, появляется необходимость анализа языка с точки зрения лингвокультурного и антропоцентрического аспектов. Тем самым в статье приводится анализ междометных единиц как средства выражения эмоциональной составляющей высказываний, т.к. именно они являются важнейшим показателем переживаний и чувствований человека и отражают лингвокультурологическое своеобразие языка.

Предметом исследования являются междометные слова адыгских языков, разбор семасиологических, морфологических, текстообразующих аспектов исследований и их функциональная характеристика.

Для достижения цели ставятся следующие задачи:

1. Показать, что междометия выступают одним из важнейших языковых знаков эмотивной лексики. 
2. Подтвердить, что они ориентированы на собеседника, на оживление его внимания, вовлечение его в процесс коммуникации и являются текстообразующей единицей, что междометия могут использоваться как эквиваленты предложений.

3. Определить их лингвокультурологические особенности и роль в образовании фразеологических единиц.

Практическая значимость статьи заключается в том, что итоги исследования могут быть полезны при обучении адыгским языкам в вузах, колледжах гуманитарных направлений, в общеобразовательных учреждениях, также могут быть применены при проведении тематических семинаров и спецкурсов для изучения практических, теоретических, сравнительных исследований по различным языкам. Полученные данные могут быть использованы при создании грамматических, лексикографических, учебных изданий и пособий, т.к. в работе приводятся материалы, ранее не описанные в исследовательских трудах по адыгским языкам.

Разработка междометий в адыгском языкознании является малоисследованным пунктом лингвистики, поэтому существуют некоторые расхождения относительно их семантических, функциональных, грамматических, синтаксических характеристик. Статья направлена на раскрытие функционально-коммуникативных свойств междометий и привнесение своего посильного вклада в теоретический и практический процесс их анализа.

При написании работы мы опирались на несколько методов лингвистических исследований. При отборе иллюстративного и научного материала мы прибегали к сравнительному и обобщающему методам, затем был проведен анализ подобранной информации. После чего производились сравнительно-сопоставительные работы, где привлекались материалы из родственного адыгейского языка. При исследовании семантики и структуры междометных единиц мы обращались к структурно-семантическому методу. В работе использовался также метод классифицирования, чтобы систематизировать рассматриваемые слова.

Теоретическую базу исследования составляют труды следующих лингвистов-кавказоведов. Первым исследователем в адыгском языкознании, кто выделил междометия среди частей речи, был Ш. Б. Ногмов [14]. В последующем интеръективизмы изучались многими адыговедами. К примеру, Т. М. Борукаев впервые в адыгской лингвистике дал определение междометиям и отделил их от звукоподражательных слов [5]. Н. Ф. Яковлев и Д. Ашхамаф утверждали, что междометия являются древнейшими элементами языка [23], их мнение поддерживал Х. Ш. Урусов [19]. Г. Ф. Турчанинов и М. Цагов утверждали, что междометия не являются категорией морфологической и не могут рассматриваться в пределах грамматики [18]. М. Л. Апажев выделял междометия как особый разряд неизменяемых слов [1]. А. А. Шаов поднимал вопрос о проблемах разграничения междометий и звукоподражательных слов и их лексикографизации [22]. Наиболее обстоятельно подошел к разработке данного раздела знаменитый на весь мир кавказовед М. А. Кумахов [9]. Также междометия упоминались в работах А. К. Шагирова [21], Х. Т. Таова [16], Н. Т. Гишева [6], К. Х. Меретукова [11], У. С. Зекоха [8] и ряда других лингвистов.

\section{Междометия как элемент эмотивной лексики}

Учитывая тот факт, что междометия являются основным сопровождающим элементом эмфатической сферы человека, они представляются неотъемлемой частью эмоциональной лексики. Как пишет М. Х. Токмакова, междометные слова имеют большое значение в эмотивной лексике, т.к. с их помощью выражаются различные эмоции [17]. Вербальные средства отражения эмоций и чувств давно стали объектом пристального внимания исследователей, т.к. выражение отношения субъекта речи к сказанному становится первостепенной функцией междометий. Они «составляют естественную и неотъемлемую принадлежность эмоциональной разговорной речи, придают ей выразительность и способствуют более точному достижению цели коммуникации» [10].

Бесспорно, что исследуемые слова не имеют смысловой нагрузки, не выполняют ни номинативной, ни синтаксической функции. Тем не менее являются аффективной единицей, где главным признаком выступает все многообразие оттенков чувств и эмоций, испытываемых человеком, которые могут быть как синонимичными, так и совершенно противоположными по смыслу.

Исследуемый раздел лексики широко представлен как в кабардино-черкесском, так и в адыгейском языке. По признаку принадлежности к среде чувств и эмоций их можно разграничить на три группы: положительные, отрицательные и многозначные. Анализ показывает, что в речи больше всего используются междометия, передающие отрицательные эмоции, составляющие 8 подгрупп, положительные междометия насчитывают 3 основные подгруппы, многозначные (универсальные) - 4 [3, с. 53-59]. По наблюдениям психологов, в языковом формате положительные эмоции в речи человека проявляются гораздо в меньшей степени, чем отрицательные. Объясняется это не тем, насколько чаще человек впадает в отрицательное эмоциональное состояние, а тем, что «отрицательные эмоции значительно чаще каузируют как сам процесс коммуникации, так и свою языковую экспликацию в процессе речевого общения» [20].

\section{Дискурсообразующая функция и просодическое оформление междометий}

В синтаксическом плане междометные слова, вопреки утверждениям некоторых лингвистов, располагают обширным ресурсом. Хоть и занимают независимую позицию, вместе с тем они применяются в абсолютном соответствии со смыслом всего выражения. Анализ междометий как дискурсо- и текстообразующих единиц, 
как средства привлечения внимания собеседника и вовлечения его в процесс коммуникации стал актуальным сравнительно недавно. До некоторых пор их рассматривали только с одной стороны - в качестве способа передачи эмоционального состояния говорящего.

Как показывают наши наблюдения, для определения выражаемой эмоции нет необходимости выстраивать длинные предложения. Свое отношение к происходящему можно показать с помощью междометных слов.

К примеру: (Хьэмид, Батыр хуэгбэзауэ:) - EI, бетэмал!.. а зэрыжыпІам хуэдэу, а Захаров жыхуэпІэ лІы дэгъуэр яукІамэ, хъуакъым [7, н. 104]. / «(Хамид, обращаясь к Батыру:) - О, господи!.. Если, как ты говоришь, убили этого статного мужчину Захарова, это плохо» (здесь и далее перевод автора статьи. - А. А.). В предложении междометие eI, бетэмал! передает чувство глубокого беспокойства и сожаления за погибшего, которое становится понятным и без последующего высказывания. Автор дополняет выражение, чтобы более широко раскрыть переживания говорящего.

Бытует мнение, что междометия являются лишь экспрессивным выкриком. Оспаривая его, мы можем утверждать - в предложение они включаются не стихийно. Напротив, междометия не только несут эмоциональную нагрузку и неразрывно связаны с основным суждением, более того, в языке нередко встречаются примеры, где предложение состоит лишь из одного междометия, выступая как эквивалент целому высказыванию, которое несет в себе весь эмоциональный смысл и выполняет большую коммуникативную функцию. Эту мысль подтверждает и А. В. Ордули, заявляя, что все лексемы разбираемой части речи способны применяться как законченное высказывание [15]. Например: - Мыдрей пащтыхыыдзэм пащтыхь дворецри иубыдри ари яхбунщІащ къалэм и адрей унэхэр зэрахъунщІам ещзхыркъабзэу, къыбгурыІуа, Къаирбэч! - Ахъу! [13, н. 192]. / «Другое царское войско захватило царский дворец и разорило его, так же как и другие дома этого города, понимаешь, Каирбек! - Ого!». В данном варианте мы понимаем, что междометие ахъу и без дальнейшего высказывания передает чувство удивления. Причиной этого феномена является то обстоятельство, что в диалоге мы стараемся сократить выговариваемый текст, замещать односложными и наиболее простыми предложениями, чтобы избежать чрезмерно большого объема информации и нагроможденности. Немаловажную роль в передаче данной информации имеют мимическое, интонационное, жестовое сопровождение и контекст. Все это вместе взятое с эмоциональным содержимым и способствует образованию текста.

Роль интонации особенно важна, когда междометия используются без контекста, т.к. по сути своей они многозначны и получают определенный смысл в контексте. И здесь вспомогательным инструментом выступают невербальные средства общения, с помощью которых адресат получает более подробную информацию о переживаниях человека. Благодаря жестам и мимике можно догадаться, какие чувства человек испытывает в данной ситуации и какую смысловую нагрузку несет используемое выражение. В живой коммуникативной ситуации именно просодическое оформление помогает наверняка определить семантику междометия.

По этой причине, ничуть не умаляя значения контекста в распознавании смысловой составляющей междометных слов как в художественных произведениях, так и в живой разговорной речи, собственно, интонация помогает понять истинное и правильное толкование используемых интеръективизмов. Просодика в тексте становится необходимой деталью, которая обрамляет, дорабатывает и «декорирует» междометие. Таким образом, интонация превращается в необходимый дополнительный элемент акустического строения языка.

\section{Лингвокультурные особенности междометий}

В последние годы междометия начали рассматриваться с точки зрения лингвокультуры и национального своеобразия отдельного народа. Взаимосвязью культуры и языка исследователи интересовались во все времена, поскольку «язык представляет собой главную форму выражения и существования национальной культуры» [4]. Как известно, разными языковыми элементами, дискурсообразующими единицами формируется соответственный образ мира народа. Для полноценного изучения лингвокультуры адыгских языков мы считаем необходимым привлечь все языковые средства, где немаловажное значение занимают междометия как представители древнейшего пласта языка. Доказательством их архаичности служит то обстоятельство, что простые междометные слова не подлежат переводу, к ним можно лишь подбирать соответствия из других языков или же описывать переживаемые эмоции: аІей - «ай», «ой», «ах» (выражает удивление, восклицание); аууей - «да ну», «да нет же» (выражает сожаление, сочувствие); бетэмал - «ах», «ох», «боже» (выражает сожаление, досаду); гуІэгъуэ (мыгъуэ) «господи», «боже», «ужас» (выражает ужас, испуг); дыдыд - «ой-ой-ой» (выражает чувство сожаления, огорчения, отвращения); елъ ар! - «смотри на него» (выражает досаду, упрек, осуждение) и т.д. [2, с. 26-32].

Междометия - это открытый, до конца не сформированный класс слов, число которых еще не определено. В словарях адыгских языков мы нашли чуть больше 100 слов. Нами обнаружено из художественных произведений, разговорной речи носителей языка свыше 500 слов, что свидетельствует о пополнении и обогащении их количества. Здесь уместно отметить справедливое замечание И. И. Мещанинова в том, что «междометия продолжают создаваться при развитой речи вовсе не как случайные выкрики, а как слова» [12, с. 354].

\section{Междометные фразеологические единицы}

Среди подобранного материала мы находим большое количество устойчивых выражений - фразеологизмов. Они широко представлены в адыгских языках, и анализ способов их образования вызывает особый интерес. 
В подобном процессе фигурируют практически все части речи. Нередки случаи образования фразеологических единиц с участием междометных слов: лэу-лэу щІын - лечь спать; пу нэлат ехын - проклясть кого-л.; уэуэур и махуэт - вопить, кричать; уэуитІ гъэшын - сильно плакать, вопить; уэху алыхь жегъэІэн - дать передышку; уей-уей жегъэІэн - прославиться и т.д. В зависимости от вербальных обстоятельств в разряд междометий могут переходить также фразы, обладающие повышенной экспрессивностью, например: азэлыхьталэр (алыхьыр) согъэпцI - «клянусь»; е гъуэгу махуэ ежьэн - выражает осуждение, неодобрение; е зи унагъуэрэ - «подумать только!», «надо же!»; ди тхьэ - «боже» и т.д.

Междометные фразеологизмы по своим характеристикам схожи с междометиями тем, что не называют явлений и предметов, выражают эмоции, не выполняют синтаксической функции и не являются членом предложения. В высказываниях имеют обособленную позицию, тем не менее тесно связаны с общим значением. Они создают определённый стилистический фон выражения, вносят колорит и экспрессию, яркость и красочность, служат для обогащения речи и являются типичными для структуры кабардино-черкесского языка.

Междометные фразеологизмы, как и фразеологические единицы, уже присутствуют в языке как неизменяемая, целостная форма с определенным грамматическим строением и семантикой. Они извлекаются из глубин памяти человека как готовые выражения. Короткие, выразительные обороты речи отражают этническую ценность, память о событиях и личностях, которые являются доказательством мудрости, знаний, традиций, образа жизни народа и отношения к окружающим. В адыгских языках мы находим огромное количество междометных фразеологизмов, знание и умелое использование которых свидетельствуют о высоком уровне владения языком.

\section{Заключение}

Языковеды, исследовавшие междометия адыгских языков, в большинстве случаев указывали на их индивидуальные, универсальные свойства. В нашем исследовании мы пришли к следующим выводам: междометия выступают одним из главных представителей эмотивной лексики, они уникальны и многофункциональны, с определенным своеобразным звуковым оформлением, тесно связанным с интонацией, жестами и мимикой. Доказано, что они принимают участие во многих процессах формирования человеческого языка и играют значительную роль в построении дискурсивной речи, помогают в выявлении лингвокультурных особенностей языка. Среди прочих характерных черт в них проявляется все многообразие просодического модифицирования. В работе мы утверждаем, что междометия используются в предложениях в полном соответствии с его смысловым содержанием. Более того, интеръективизмы несут обширную коммуникативную нагрузку, являясь текстообразующими единицами, которые могут выступать эквивалентом предложения. В статье описываются два способа образования фразеологических единиц: первый - с участием междометий, второй - без их участия, но выполняющие в языке функции междометий. Также приводится сравнение их как с простыми междометиями, так с фразеологическими единицами. Как видно из работы, интеръективизмы играют немаловажную роль в образовании подобных устойчивых выражений.

Междометные слова составляют достаточно большой объем лексики адыгских языков. В кавказских языках процесс изучения междометий еще не закончен. Перспективы дальнейшего исследования видим в том, что многие спорные и малоизученные моменты еще ждут своего решения, к примеру образование и функционирование в речи междометных фразеологических единиц.

\section{Источники | References}

1. Апажев М. Л. Современный кабардино-черкесский язык. Лексикология. Лексикография. Нальчик: Эльбрус, 2000. 408 с.

2. Афаунова А. А. Вариативность и трудности в переводе междометий (на материале русского и кабардиночеркесского языков) // Научный диалог. 2020. № 3. С. 24-37.

3. Афаунова А. А. Семантико-грамматический анализ междометий и звукоподражаний кабардино-черкесского языка. Нальчик: Издательский отдел КБИГИ, 2012. 128 с.

4. Ахметзянова Ф. С., Усманова Ф. С. Языковая картина мира и лингвокультурология [Электронный ресурс]. URL: https://www.elibrary.ru/item.asp?id=24407391 (дата обращения: 22.04.2021).

5. Борукаев Т. М. Грамматика кабардино-черкесского языка / под ред. Н. И. Голубинского. Нальчик: КабардиноБалкарский облнациздат, 1932. 142 с.

6. Гишев Н. Т. Сравнительный анализ адыгейских языков. Майкоп: Качество, 2003. 284 с.

7. ДыщэкI М. Пшэплъ: роман. Япэ Іыхьэ. Ещанэ къыдэкІыгъуэ. Черкесск: Ставрополь тхылъ тедзапІэ, Къэрэшей-Шэрджэс отделенэ, 1990. 288 н.

8. Зекох У. С. Адыгейская грамматика. Майкоп: Адыгея, 2002. 512 с.

9. Кумахов М. А. Морфология адыгских языков. Синхронно-диахронная характеристика. Нальчик: КабардиноБалкарское книжное издательство, 1964. 272 с.

10. Меметова А. Ш. Междометия как средства выражения эмоций в крымско-татарском и немецком языках [Электронный ресурc]. URL: https:/www.elibrary.ru/item.asp?id=34963194 (дата обращения: 27.04.2021).

11. Меретуков К. Х. Мимео-изобразительные слова в адыгейском языке // Вопросы адыгейского языкознания. 1984. Вып. IV. С. 18-25. 
12. Мещанинов И. И. Члены предложения и части речи. М.: Наука, 1978. 387 с.

13. Нало А. Нэхущ шу: роман. Налшык: Эльбрус, 1990. 359 н.

14. Ногмов Ш. Б. Филологические труды: в 2-х т. / исслед. и подг. к печ. Г. Ф. Турчанинов. Нальчик: Кабардино-Балкарское книжное издательство, 1956. Т. 1. 308 с.

15. Ордули А. В. Междометие как средство репрезентации эмотивного компонента языка [Электронный ресурс]. URL: https://www.elibrary.ru/item.asp?id=17783053 (дата обращения: 25.04.2021).

16. Тау Хь. Т., Урыс Хь. Щ. Адыгэбзэмрэ адыгеибзэмрэ я грамматикэ: (Зэлъытауэ). Налшык: КБГУ, 1995.119 н.

17. Токмакова М. Х. Эмотивная лексика кабардино-черкесского языка. Нальчик: Издательство М. и В. Котляровых, 2017. 274 с.

18. Турчанинов Г., Цагов М. Грамматика кабардинского языка. М. - Л.: АН СССР, 1940. 160 с.

19. Урыс Хь. Щ. Адыгэбзэ граматикэ. Фонетикэ. Морфонемикэ. Морфологие. Налшык: Эльбрус, 2001. 232 н.

20. Филимонова О. Е., Хомякова Е. Г. Положительные эмоции в новостном тексте [Электронный ресурс]. URL: https://www.elibrary.ru/item.asp?id=22287404 (дата обращения: 29.04.2021).

21. Шагиров А. К. Фонетика и морфология кабардинского языка. Нальчик: Эль-Фа, 2004. 222 с.

22. Шаов А. А. Принципы выделения и лексикографирования служебных, междометных и звукоподражательных слов // Вопросы адыгейского языкознания. 1984. Вып. IV. С. 53-67.

23. Яковлев Н. Ф., Ашхамаф Д. А. Грамматика адыгейского литературного языка. М. - Л.: Издательство АН СССР, 1941. $463 \mathrm{c}$.

\section{Информация об авторах | Author information}

RU Афаунова Анджела Анатольевна ${ }^{1}$, к. филол. н.

${ }^{1}$ Институт гуманитарных исследований филиал Федерального государственного бюджетного научного учреждения «Федеральный научный центр “Кабардино-Балкарский научный центр Российской академии наук” (ИГИ КБНЦ РАН), г. Нальчик

EN Afaunova Angela Anatolievna ${ }^{1}, \mathrm{PhD}$

${ }^{1}$ The Institute for the Humanities Research - Affiliated Federal State Budgetary Scientific Establishment "Federal Scientific Center «Kabardian-Balkarian Scientific Center of the Russian Academy of Sciences»" (IHR KBSC RAS), Nalchik

${ }^{1}$ martazei@mail.ru

\section{Информация о статье | About this article}

Дата поступления рукописи (received): 11.05.2021; опубликовано (published): 30.06.2021.

Ключевые слова (keywords): междометия; дискурсообразующая функция; эмотивная лексика; лингвокультурология; адыгские языки; interjections; discourse-formative function; emotive vocabulary; linguo-culturology; Adyghe languages. 